\title{
The importance of continuing adequate lifestyle including exercise, daily activity and low carbohydrate diet (LCD) for type 2 diabetes mellitus (T2DM)
}

\begin{abstract}
The case was 71-year-old male patient with type 2 diabetes mellitus (T2DM). He was diagnosed T2DM at the age of 61 associated with thirsty, polydipsia and fatigue. HbA1c value was $12.5 \%$ and blood glucose profile was $150-300 \mathrm{mg} / \mathrm{dL}$. Just after starting low carbohydrate diet (LCD), his blood glucose kept under $150 \mathrm{mg} / \mathrm{dL}$ all day long. He continued good diabetic control as HbA1c 5.8-6.8\% for 10 years. Some beneficial points are found: i) keeping LCD with the feeling not stressful but pleasant for observing the normal glucose level, ii) walking daily for 2 hours, iii) continuing diary with exercise, medicine, activities and so on, iv) writing the diary for years every day, including exercise, meal, medicine, activities and so on, v) checking post-prandial hyperglycemia by meal tolerance test (MTT). For details of v), HbA1c was 6.5\% in May 2021 and fasting glucose was $107 \mathrm{mg} / \mathrm{dL}$. Glucose values 45-min and 60-min after 3 meals showed 210-201-177mg/ $\mathrm{dL}$ and 195-213-172mg/dL, respectively. His various continuing behaviors contributed satisfactory glycemic control. This article becomes reference in the diabetic practice and research.
\end{abstract}

Keywords: Low Carbohydrate Diet (LCD), Japan LCD Promotion Association (JLCDPA), meal tolerance test (MTT), Calorie Restriction (CR)
Volume 8 Issue 2 - 202I

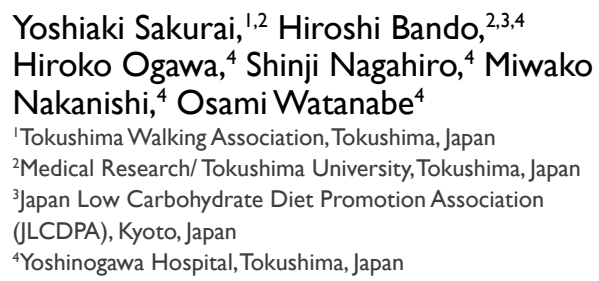

Yoshiaki Sakurai, ${ }^{1,2}$ Hiroshi Bando, ${ }^{2,3,4}$

Hiroko Ogawa, ${ }^{4}$ Shinji Nagahiro, ${ }^{4}$ Miwako Nakanishi, ${ }^{4}$ Osami Watanabe ${ }^{4}$

'Tokushima Walking Association, Tokushima, Japan ${ }_{2}^{2}$ Medical Research/Tokushima University, Tokushima, Japan 3Japan Low Carbohydrate Diet Promotion Association (JLCDPA), Kyoto, Japan

${ }^{4}$ Yoshinogawa Hospital, Tokushima, Japan

Correspondence: Hiroshi BANDO, Tokushima University / Medical Research, Address: Nakashowa I-6I,Tokushima 770-0943 Japan, Tel +8I-90-3I 87-2485,

Email pianomed@bronze.ocn.ne.jp

Received: July 16, 202I | Published: July 27, 2021

\section{Introduction}

Diabetes mellitus (DM) has been globally crucial issue from medical and social points of view. ${ }^{1}$ It may give burden to each patient, society and country. ${ }^{2}$ The prevalence and incidence of DM and noncommunicable diseases (NCDs) have been elevated remarkably in developing and developed countries worldwide. ${ }^{3}$ As to theirtreatment for DM, some options have been present, including several kinds of oral hypoglycemic agents (OHAs) and other injectable diabetic agents. ${ }^{4}$

Recently, for the treatment of DM, new drugs have been evaluated as effective in actual diabetes treatment.

They include dipeptidyl peptidase-4 inhibitor (DPP-4i), glucagonlike peptide 1 receptor agonist (GLP-1RA), long-acting insulin, sodium-glucose transporter 2 inhibitor (SGLT2i) and so on. However, it is not recommended to administer rather new agents for all cases. In some cases, the standard drug metformin and the slightly previous sulfonylurea (SU) provide good diabetic control. ${ }^{6}$ Therefore, it is necessary to consider appropriate treatment according to various factors such as the characteristics of the case.

On the other hand, the authors have been involved in diabetes care and research, as well as educational activities. Among them, Sakurai has carried out various projects as the former president of Tokushima Prefecture Walking Association (TPWA), and has held some lectures, workshops and walk rallies. Bando provided an overview and implementation of diabetes, treatment of diabetes and low carbohydrate diet (LCD) in its project. From historical point of view, LCD was initiated by Drs. Atkins and Bernstein in Western countries. ${ }^{7,8}$ Then, LCD has been widely known in medical and health care region. ${ }^{9}$ Successively, LCD was started by our co-researcher Dr. Ebe in Japan, and LCD has been gradually understood and prevalent for years..$^{10}$

We have established Japan LCD promotion association (JLCDPA) and developed LCD through various activities. ${ }^{11}$ They include workshops, seminars, books, medical societies and related opportunities. ${ }^{12}$ In order to inform the practical method of LCD, three types have been introduced. ${ }^{13}$ They are super-LCD, standard-LCD and petite- $\mathrm{LCD}$, including carbohydrate amount ratio as $12 \%, 26 \%$ and $40 \%$, respectively. ${ }^{14}$

Among our clinical practice for patients with DM and various complications and pathologies, we have experienced an impressive patient. The case is 71-year-old diabetic men who has been in good control situation associated with some characteristic points. The outline of the case and related discussion would be described in this article.

\section{Case presentation}

\section{Present history:}

The case was 71-year-old male patient. When he was 50 years old, he had health check-up and then was pointed out to have a tendency of diabetes. After that, he received diabetic treatment intermittently, because his $\mathrm{HbAlc}$ was not so high. He had the fracture of right ankle during climbing the mountain at the age of 55. Successively, he had the operation for inguinal hernia. 
There has been various influence between his diabetic management and his social history. During his fifties, he had been one of the directors of Tokushima Walk Ralley Association (TWRA), and became the president of TWRA from 2012. He had a variety of matters to be dealt with for long time. Among various events, there were important annual "Walking Ralley with diabetic patients in Tokushima". On April 2015, this event and lecture was conducted by authors of Sakurai and Bando followed by successful achievement.

When he was 61 years old, he felt thirsty, polydipsia, polyuria, fatigue and visited diabetic department of the hospital in Tokushima. As a result, he was proved to have extremely high HbAlc as $12.5 \%$. He received fundamental examinations of biochemical test, complete blood test, chest X-P, ECG and so on. Remarkable abnormality was not detected.

He was at once advised to start and continue the nutritional method of super-low carbohydrate diet (LCD). It includes $12 \%$ of carbohydrate, in which the patient restricts bread, rice, noodle, pizza or other carbohydrate foods. The clinical progress was shown in Figure 1. Before starting LCD, his daily profile of blood glucose ranged from $150 \mathrm{mg} / \mathrm{dL}$ to $300 \mathrm{mg} / \mathrm{dL}$. Just after beginning of superLCD, his glucose decreased almost below $150 \mathrm{mg} / \mathrm{dL}$. His HbA1c value was $12.5 \%, 10.5 \%, 8.0 \%$ and $6.7 \%$ from June to September, respectively. It showed remarkable improvement.

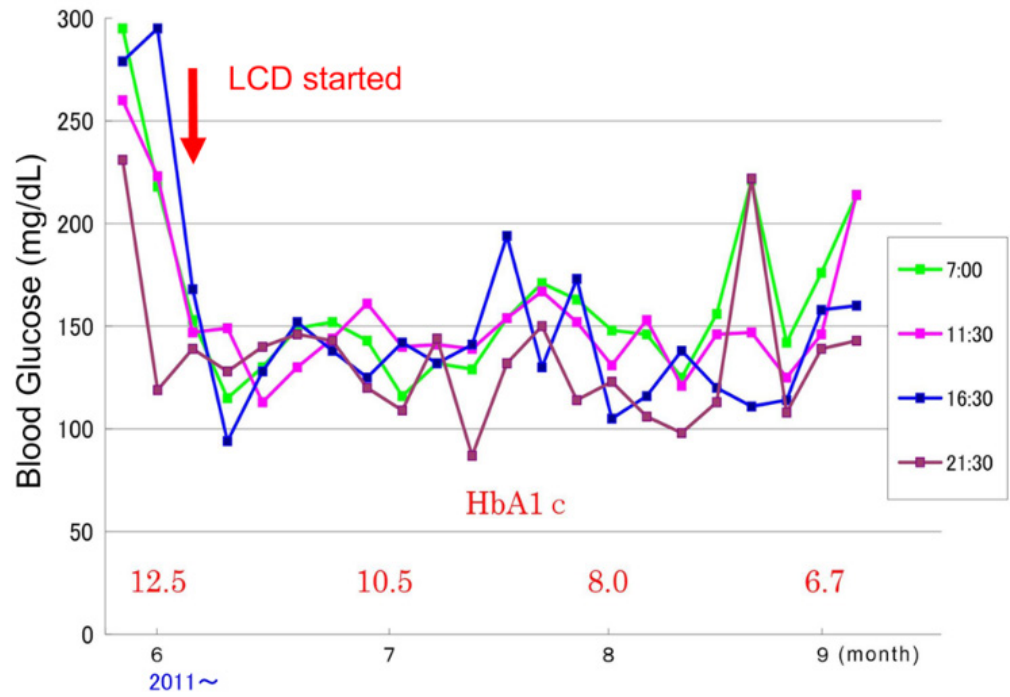

Figure I Rapid improvement of glucose variability by Low Carbohydrate Diet (LCD).

Physical examination: His physical status and examination results at the age of 61 were in the following.

The consciousness was normal, and vitals were also within normal range. Unremarkable abnormality was detected for the chest and abdomen. He did not complain of neurological abnormality such as diabetic neuropathy. Furthermore, no diabetic symptoms and signs were found such as retinopathy or nephropathy.

Regarding his physique, the stature has been $173 \mathrm{~cm}$, and body weight was $64 \mathrm{~kg}, 59 \mathrm{~kg}$, and $54 \mathrm{~kg}$ when he was 50,61 and 71 years old, respectively.

Examinations: As to his laboratory tests, twice checks per year were continued so far. Current data on June 2021 for biochemistry and complete blood count (CBC) are summarized: AST $17 \mathrm{U} / \mathrm{mL}$, ALT 14 $\mathrm{U} / \mathrm{mL}, \mathrm{r}-\mathrm{GT} 20 \mathrm{U} / \mathrm{mL}$, BUN $17 \mathrm{mg} / \mathrm{dL}$, Cre $0.7 \mathrm{mg} / \mathrm{dL}$, eGFR $79 \mathrm{~mL} /$ $\mathrm{min} / 1.73 \mathrm{~m}^{2}$, Uric Acid $5.3 \mathrm{mg} / \mathrm{dL}$, TG $67 \mathrm{mg} / \mathrm{dL}$, LDL $130 \mathrm{mg} / \mathrm{dL}$, HDL 65 mg/dL, CRP $0.01 \mathrm{mg} / \mathrm{dL}$, TP $6.2 \mathrm{~g} / \mathrm{dL}$, Alb 4.4 g/dL, Hb 12.8

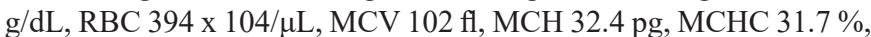
WBC $3900 / \mu \mathrm{L}$, Plt $16.4 \times 104 / \mu \mathrm{L}$. Other fundamental examinations were in the following: chest X-P negative, ECG ordinary sinus rhythm and unremarkable ST-T changes and abdominal CT unremarkable.

\section{Results}

His diabetic condition was improved by LCD diet in JuneSeptember 2011. Since then, the control situation has been stable and excellent. Among these, Figure 2 shows the clinical course of recent 1.5 years from 2020 to June 2021. Among them, HbA1c is stable from $5.8 \%$ to $6.7 \%$. The daily fluctuation of blood glucose is performed once a week, and the blood glucose range is within the normal range of $80-120 \mathrm{mg} / \mathrm{dL}$.

His treatment can be summarized from three perspectives.

1. Super-LCD has been continued satisfactory with his own will, which is not stressful but pleasant for observing the normal data of glucose.

2. He has been walking for more than 2 hours every day for many years with aerobic exercise therapy in his usual daily life Table 1.

3. Pharmacotherapy is based on Metformin 750mg and Linagliptin $5 \mathrm{mg}$. However, these two agents were not enough for ideal diabetic control. Then, adding $0.5 \mathrm{mg}$ of glimepiride makes it successful without adverse effect or hypoglycemia (Figure 2).

As mentioned above, these situations $(1,2,3)$ have been continued for long as an ideal treatment for himself.

Furthermore, there are the important fourth and fifth factors.

4. His diary has been properly written every day for many years. It properly describes diet, exercise, medicine, daily activities, walking association activities, shopping, vaccination and so on. (Table 1). 
5. Recently, he conducted a Meal Tolerance Test (MTT). MTT was performed twice on May, 2021. The daily diet was almost unchanged, and blood glucose was measured 45 minutes and
60 minutes after the meals. As a result, it became clear that the blood glucose increased to around $200 \mathrm{mg} / \mathrm{dL}$ depending on the carbohydrate intake (Table 1).

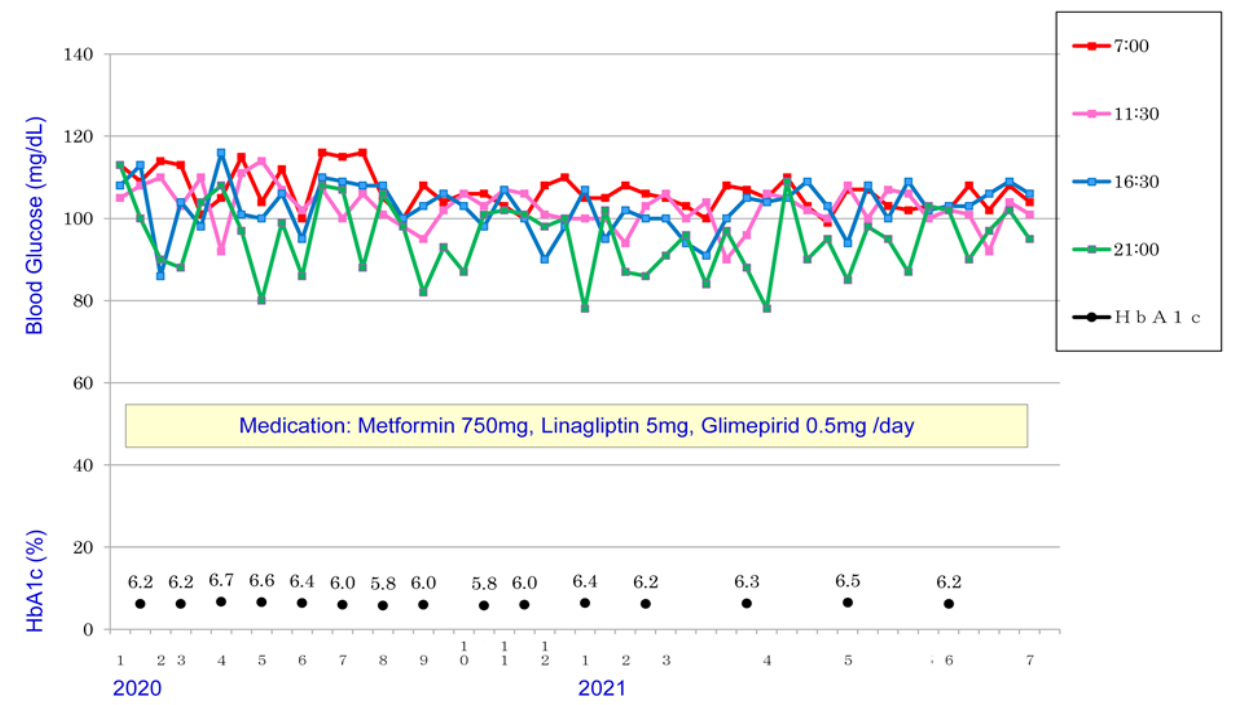

Figure 2 Stable glucose variability of daily profile of blood glucose by LCD.

Table I Daily lifestyle record of meal, exercise, activity and blood glucose variability during May-June, 202 I

\begin{tabular}{|c|c|c|c|c|}
\hline Month & Day & Hosp Dept & $\begin{array}{l}\text { Glucose Profile } \\
0700-1130-1630-2100 \mathrm{~h}\end{array}$ & Diary of meal, exercise and behaviour during May and June, 202I \\
\hline \multirow[t]{17}{*}{ May } & I & Diabetes & & $\mathrm{HbAlc} 6.5 \%$, raining outside, reading \& rest in PM, walk $75 \mathrm{~min}$ in evening \\
\hline & 3 & & $107-108-94-85$ & usual ADL shopping outside in AM, $125 \mathrm{~min} \&$ rest in PM, walking $65 \mathrm{~min}$ evening \\
\hline & 5 & & & I) Meal Tolerance Test (45-min): post-prandial glucose was measured. \\
\hline & & & & breakfast-45min: $210 \mathrm{mg} / \mathrm{dL}$, tomate soup, egg, bacon, cabbage, onion and protein \\
\hline & & & & lunch-45min: $201 \mathrm{mg} / \mathrm{dL}$, boiled beef,tofu, salad with egg, onion \\
\hline & & & & supper-45min: $177 \mathrm{mg} / \mathrm{dL}$, hamburger, tofu, vegitable salad, miso soup, noodle \\
\hline & 6 & & & shopping outside in AM, II5min \& rest in PM, walking 70min evening \\
\hline & 8 & & & 2) Meal Tolerance Test (60-min): post-prandial glucose was measured. \\
\hline & & & & breakfast-60min: $195 \mathrm{mg} / \mathrm{dL}$, tomate soup, egg, bacon, cabbage, onion and protein \\
\hline & & & & lunch-60min: $213 \mathrm{mg} / \mathrm{dL}$, Japanese pizza with flour, pork, leek and paste food \\
\hline & & & & supper-60min: I 72 mg/dL, hamburger, tofu, vegitable salad, miso soup, noodle \\
\hline & 10 & & $107-100-108-98$ & usual $\mathrm{ADL}$ \& reading in $\mathrm{AM}$, walking $110 \mathrm{~min}$ \& rest in $\mathrm{PM}$, walking $50 \mathrm{~min}$ evening \\
\hline & 15 & & & Meeting of Tokushima Walking Association in AM, walk 120 min in PM, rest in even' \\
\hline & 16 & & & Ist vaccine of COVID-19, shopping \& reading in AM, rest in PM and evening \\
\hline & 17 & & $100-107-100-95$ & usual $\mathrm{ADL}$ \& reading in $\mathrm{AM}$, reading \& rest in PM, walking $55 \mathrm{~min}$ in the evening \\
\hline & 25 & & $102-106-109-87$ & usual $\mathrm{ADL}$ \& reading in $\mathrm{AM}$, walking $110 \mathrm{~min} \&$ rest in $\mathrm{PM}$, walking $65 \mathrm{~min}$ evening \\
\hline & 31 & & $103-100-102-103$ & usual $\mathrm{ADL}$ \& reading in $\mathrm{AM}$, walking $105 \mathrm{~min} \&$ rest in $\mathrm{PM}$, walking $75 \mathrm{~min}$ evening \\
\hline \multirow[t]{5}{*}{ June } & 5 & Diabetes & & HbAIc 6.2\%, ECG:WNL, walk I35min \& rest in PM, walk $55 \mathrm{~min}$ in evening \\
\hline & & & & Taken tomato soup $100 \mathrm{~g}$. It includes carbohydrate $4.4 \mathrm{~g}$ in $100 \mathrm{~g}$ of it. \\
\hline & 6 & & & 2nd vaccine of COVID-19 in AM, reading in library in PM, rest in the evening \\
\hline & 7 & & & fatigue from vaccine of COVID-19, rest, in AM and PM, walk 65 min in evening \\
\hline & 8 & & $102-102-103-102$ & usual $A D L$ \& reading in $A M$, walking $90 \mathrm{~min} \&$ rest in $P M$, walking 75 min evening \\
\hline
\end{tabular}




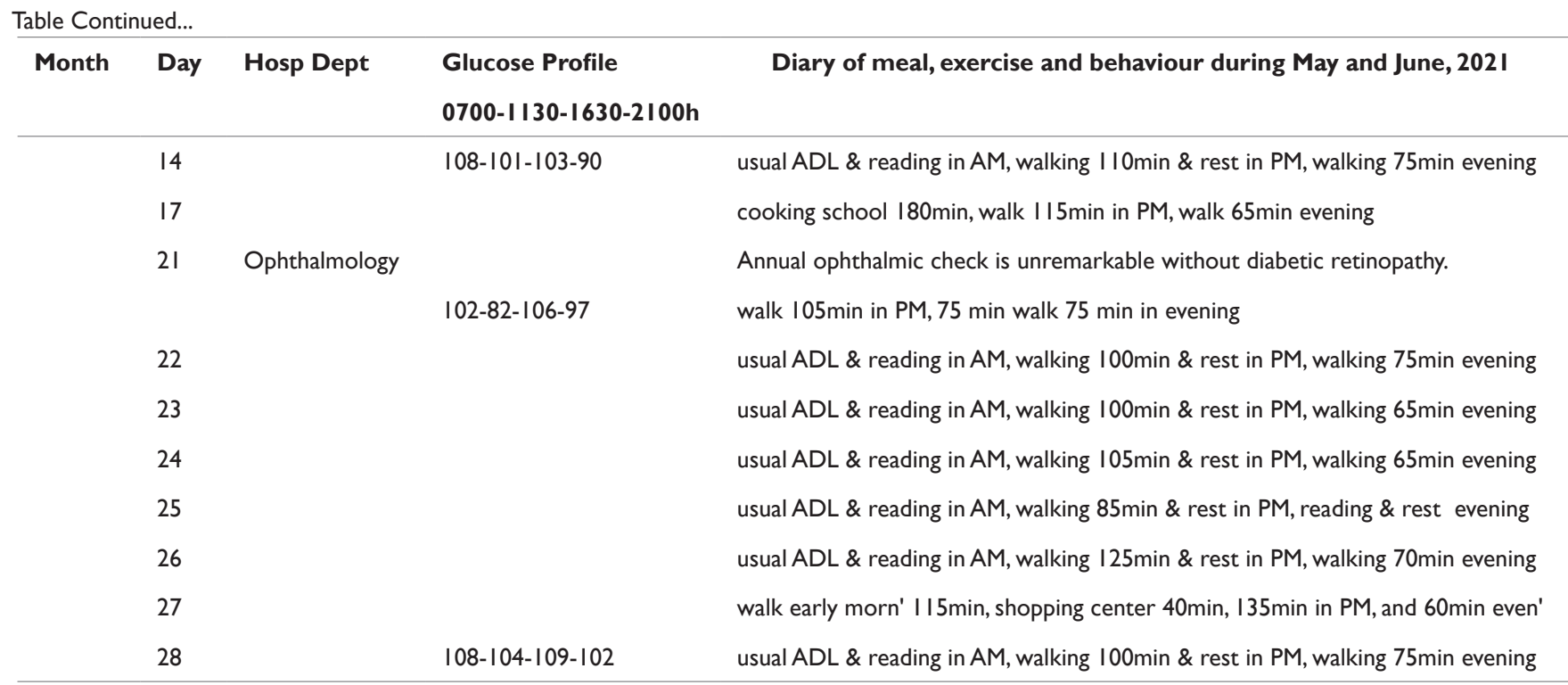

\section{Ethical considerations}

This case report has been in itself conducted with the ethical principles on the Declaration of Helsinki. Further, additional comment was presented from the Ethical Guidelines for Research for Humans, associated with the perspectives of Good Clinical Practice (GCP). The authors who are related to this report established an ethical committee, which includes the president of the hospital, physician, head-nurse, pharmacist, nutritionist as well as the professional of legal specialty. Discussion has been performed with adequate manners, and it has decided to the agreements for this research protocol. The informed consent and written document agreement have been taken from the case.

\section{Discussion}

Nutritional treatment for diabetes and related information of LCD have been important. From basic medical point of view, the mechanism of carbohydrate and post-prandial hyperglycemia is described in the famous biochemistry textbook..$^{15}$ It is known that animals are not equipped defence mechanisms for hyperglycemia and that insulin is the only present hormone acting for decreasing blood glucose. Human is one of the animals and/or mammals. For the metabolic mechanism in human, carbohydrate $1 \mathrm{~g}$ can increase blood glucose $1 \mathrm{mg} / \mathrm{dL}$ for ordinary healthy person, $3 \mathrm{mg} / \mathrm{dL}$ in patient with T2DM and $5 \mathrm{mg} / \mathrm{dL}$ in patient with T1DM. ${ }^{15}$

American Diabetes Association (ADA) has traditionally published standard findings and guidelines for diabetes.

It presented "Life with Diabetes" in 2004 that carbohydrate is the only nutrient which raise post-prandial blood glucose values ${ }^{16}$ (ADA2004). Successively, ADA described the Statement on the efficacy LCD in 2008. ${ }^{17}$

Clinically obtained efficacy for LCD was shown for the comparison study for calorie restriction (CR, low-fat diet), Mediterranean diet, and LCD. ${ }^{18}$ It was firstly provided evidence for clinical practice of LCD. In United States and European countries, the perspective of the concept "Carb count method" 19 and the Mediterranean diet ${ }^{20}$ have been known to have clinical effect. Consequently, in medical practice, clinical usefulness for LCD has been informed rather widely in the healthcare area and medical practice.
This case showed a significant improvement by applying LCD in 2011. Elevated blood glucose was disappeared from the first day on the initiation of LCD (Figure 1). The reason would be simply that nutritional elements other than carbohydrate do not raise blood glucose. ${ }^{15}$ Three types of LCD can be used, which are super-, standard, andpetite-LCD. When diabetic situation is severe, it may be necessary to apply super-LCD. ${ }^{14}$ Blood glucose level does not drop in the short term with previous treatment of calorie restriction (CR). It is expected that super-LCD treatment will become the standard way for initial nutritional treatment for severe diabetes in the future. When the LCD is started to diabetic patients, they will feel comfortable without hungry sensation because of hyperketonemia..$^{21}$ Therefore, the initial introduction for LCD would be actually rather easy without difficulty.

This case has continued super-LCD for years with stable HbA1c level. He has spent his daily lifestyle and eating habit along with LCD food pyramid method. ${ }^{22}$ His body weight was decreased from $59 \mathrm{~kg}$ to $54 \mathrm{~kg}$ for 10 years.

From our previous report of LCD practice for thousands of obesity patients, approximately $25 \%$ of cases have achieved $10 \%$ of weight reduction. ${ }^{23}$ LCD seems to be effective in the light of glucose variability and weight control. ${ }^{22}$

For the diabetic treatment, he was administered metformin and linagliptin as a basis. When a small amount of glimepiride $0.5 \mathrm{mg}$ (sulfonylurea agent) was added, the diabetic control became satisfactory level..$^{24}$ One of the reasons would be that his physique is rather slender without obesity, fatty liver or accumulated visceral fat.

Pathophysiology of diabetes includes both of increased insulin resistance and decreased insulin secretory function. The latter would be involved in the main mechanism for this case. ${ }^{25}$ Sulfonylurea agent can stimulate insulin secretion from pancreas, and may increase the weight of thin elderly. ${ }^{26}$ In this case, weight was gradually decreased for 10 years. The combination of three OHAs seemed to be adequate from long perspectives.

There are two other important matters concerning this case. One is the influence of psychological stress on diabetes control. ${ }^{27}$ From social point of view, this case led a stressful life for years as the president of the Tokushima Walking Association (2012-2016). After that, his fundamental lifestyle remained unchanged, but a decrease in $\mathrm{HbAlc}$ 
was observed by an average of about $0.5 \%$. Thus, it was suggested that daily psychological stress affects the glycemic response. The other is a diary kept for long years. It includes everything from daily activities, diet, exercise, blood glucose, medical issues and activities. These contents have been highly evaluated. This continuous lifestyle recording provides a great deal of useful information. It contributes diabetic treatment and leads to the provision of the best care to the patient in charge of the doctor and medical staff.

There are some limitations to this report. Some factors are not clarified in the evidence-level perspectives. They include i) actual correct carbohydrate intake amount per day in LCD meal style, ii) absence of measuring carbohydrate amount in meal tolerance test (MTT), iii) presence of multifactorial influence of stable glucosevariability from meal, exercise, oral hypoglycemic agents (OHAs), psychological stress and so on.

In summary, T2DM case has continued glucose variability for long years. For this satisfactory achievement, there are several related factors present so far. They include LCD, continuous walking, adequate medication, understanding of diabetic information, continuing diary every day with detail activities and others. It is expected that this case report will become a reference for diabetic research in the future.

\section{Acknowledgments}

The authors acknowledge support for this research from the U.S National Science Foundation under grant CMMI-1563225.

\section{Conflicts of interest}

The authors declare no conflict of interest.

\section{Funding}

There was no funding received for this paper.

\section{References}

1. Magliano DJ, Chen L, Islam RM, et al. Trends in the incidence of diagnosed diabetes: a multicountry analysis of aggregate data from 22 million diagnoses in high-income and middle-income settings. Lancet Diabetes Endocrinol. 2021;9(4):203-211.

2. Smokovski I. Burden of Diabetes Prevalence. In: Managing Diabetes in Low Income Countries. Springer. Cham. 2021.

3. Williams R, Karuranga S, Malanda B, et al. Global and regional estimates and projections of diabetes-related health expenditure: Results from the International Diabetes Federation Diabetes Atlas, 9th edition. Diabetes Res Clin Pract. 2020;162:108072.

4. Pharmacologic approaches to glycemic treatment: Standards of Medical Care in Diabetes. American Diabetes Association. Diabetes Care. 2021;44 Suppl 1:S111-S124.

5. Yu M, Benjamin MM, Srinivasan S, et al. Battle of GLP-1 delivery technologies. Adv Drug Deliv Rev. 2018;130:113-130.

6. American Diabetes Association. Diabetes technology: Standards of Medical Care in Diabetesd. Diabetes Care. 2019;42 Suppl 1:S71-S80.

7. Bernstein R. Dr. Bernstein's diabetes solution Newly revised \& Updated. Little Brown and Company, New York, 2007.

8. Atkins RC. Dr. Atkins' new diet revolution, Harper, New York, 2002.
9. Feinman RD, Pogozelski WK, Astrup A, et al. Dietary carbohydrate restriction as the first approach in diabetes management: Critical review and evidence base. Nutrition. 2015;31(1),1-13.

10. Ebe K, Ebe Y, Yokota S, et al. Low Carbohydrate diet (LCD) treated for three cases as diabetic diet therapy. Kyoto Medical Association Journal. 2014;5:125-129.

11. Bando H, Ebe K, Muneta T, et al. Effect of low carbohydrate diet on type 2 diabetic patients and usefulness of M-value. Diabetes Res Open J. 2017;3(1):9-16.

12. Muneta T, Kagaguchi E, Nagai Y, et al. Ketone body elevation in placenta, umbilical cord, newborn and mother in normal delivery. Glycat Stress Res. 2016; 3(3):133-140.

13. Ebe K, Bando H, Yamamoto K, et al. Daily carbohydrate intake correlates with HbA1c in low carbohydrate diet (LCD). J Diabetol. 2018;(1):4-9.

14. Bando H. Useful Tips for Actual Low Carbohydrate Diet (LCD) with Super Standard and Petit-LCD Methods. EC Nutrition.2021;15(5):01-04.

15. Murray RK, Granner DK, Mayes PA, et al. Harper's Illustrated Biochemistry (Harper's biochemistry) 27th Edition. The McGraw-Hill companies, Inc. American Diabetes Association. Life with Diabetes Third Edition. Alexandria, 2004

16. American Diabetes Association. Nutrition recommendations and interventions for diabetes. Diabetes Care. 2008;31(S1):S61-78.

17. Shai I, Schwarzfuchs D, Henkin Y etal. Weight loss with a low-carbohydrate, Mediterranean, or low-fat diet. N Engl J Med. 2008;359(3):229-241.

18. Kulkarni KD. Carbohydrate counting: A practical meal-planning option for people with diabetes. Clinical Diabetes. 2005; 23(3):120-124.

19. Esposito K, Maiorino MI, Ciotola M et al. Effects of a Mediterraneanstyle diet on the need for antihyperglycemic drug therapy in patients with newly diagnosed type 2 diabetes. Ann Inter Med. 2009;151(5):306-314.

20. Bando H. Ketone Bodies have Significant Effects for Long Years Associated with Human Evolution. J Med Biol. 2019;1(2): 72-75.

21. Bando H. Effective proposal of food pyramid for understanding of low carbohydrate diet (LCD). Case Rep Rev Open Access. 2020;1(1):101.

22. Nakamura T, Bando H, Kawashima T, et al. Weight Reduction by Effective Protocol of Diet and Exercise. J Diab Obes Metab. 2019;2(1):106.

23. Kadowaki T, Wang G, Rosenstock J, et al. Effect of linagliptin, a dipeptidyl peptidase-4 inhibitor, compared with the sulfonylurea glimepiride on cardiovascular outcomes in Asians with type 2 diabetes: subgroup analysis of the randomized CAROLINA $®$ trial. Diabetol Int.2021;12:87-100.

24. Gowan J, Roller L. Disease state management: Type 2 diabetes. Australian J Pharm. 2020;101:82-90.

25. Wang S, Zhan J, Cheng M, et al. Endocrine Metabolic Diseases Group of the Chinese Geriatrics Society. Chinese Medical Association.

26. Clinical expert consensus on standard care of blood glucose for residents in senior care facility in China. 2021 edition. Aging Med. 2021;4(2):93108.

27. Sevil M, Rashid M, Hajizadeh I, et al. Physical Activity and Psychological Stress Detection and Assessment of Their Effects on Glucose Concentration Predictions in Diabetes Management. In IEEE Transactions on Biomedical Engineering. 2021;68(7):2251-2260. 